\title{
Oscillating Mechanical Stimulation of the Craniocervical Region as Physical Therapy for Chronic Migraine: A Pilot Trial
}

\author{
Makoto Shiraishi' ${ }^{1}$, Munefumi Hotta ${ }^{2}$, Tomohiro Suzuki ${ }^{3}$, Noboru Imai ${ }^{4}$ \\ ${ }^{1}$ Division of Neurology, Department of Internal Medicine, St Marianna University School of Medicine, \\ Kawasaki, Japan \\ ${ }^{2}$ Hotta Clinic, Shizuoka, Japan \\ ${ }^{3}$ Suzuki Osteopathic Clinic, Shizuoka, Japan \\ ${ }^{4}$ Department of Neurology, Japanese Red Cross Shizuoka Hospital, Shizuoka, Japan \\ Email: shira@maranna-u.ac.jp
}

How to cite this paper: Shiraishi, M., Hotta, M., Suzuki, T. and Imai, N. (2019) Oscillating Mechanical Stimulation of the Craniocervical Region as Physical Therapy for Chronic Migraine: A Pilot Trial. International Journal of Clinical Medicine, 10, 150-160.

https://doi.org/10.4236/ijcm.2019.103015

Received: February 16, 2019

Accepted: March 12, 2019

Published: March 15, 2019

Copyright $\odot 2019$ by author(s) and Scientific Research Publishing Inc. This work is licensed under the Creative Commons Attribution International License (CC BY 4.0).

http://creativecommons.org/licenses/by/4.0/

\section{(c) (i) Open Access}

\begin{abstract}
Objective: We conducted a prospective trial of oscillating mechanical stimulation (OS) of the craniocervical region as treatment for drug-refractory chronic migraine (CM). Methods: Ten patients ( 8 women, 2 men; mean age $47.0 \pm 15.1$ years) were enrolled. The treatment was administered over an 8-week period to 13,4 , and 9 sites on the face and head, neck, and upper back, respectively, at 5- to 15-pound intensity. The primary outcome measure was the number of days patients suffered a migraine (hereafter "number of migraine days"), and the secondary outcome measures were the six-item Headache Impact Test (HIT-6) and Visual Analog Scale (VAS) scores for migraine pain intensity and the nine-item Patient Health Questionnaire (PHQ-9) and the seven-item Generalized Anxiety Disorder (GAD-7) scale scores. Results: Nine patients completed treatment. The number of migraine days remained unchanged, from a mean $21.7 \pm 11.6$ days/month before treatment to $19.3 \pm 7.3$ days/month upon completion of treatment. However, the HIT-6 scores improved from $67.0 \pm 8.2$ to $61.4 \pm 7.1(p=0.007)$ after 3 weeks, $61.1 \pm$ $11.5(p=0.01)$ after 6 weeks, and $59.9 \pm 11.6(p=0.035)$ upon completion of treatment. Similarly, the VAS scores improved significantly from $7.3 \pm 1.7$ to $5.7 \pm 3.1(p=0.018)$ at 6 weeks and $4.8 \pm 2.8(p=0.011)$ upon completion of treatment. The GAD-7, PHQ-9, and allodynia scale scores remained unchanged. Conclusion: Our data suggest that OS is well tolerated and may become a feasible form of treatment for drug-resistant CM.
\end{abstract}

\section{Keywords}

Chronic Migraine, Oscillating Mechanical Stimulation, Drug Resistance, 
Nondrug Treatment, Neuromodulatory Effect

\section{Introduction}

When a patient suffers from headache on more than 15 days a month for 3 months and when the headache manifests as migraine on 8 of those 15 days, the patient is said to be suffering from chronic migraine (CM) [1]. Patients who suffer frequent headache attacks or overuse analgesics are at an increased risk of conversion to chronicity [2]. The European Headache Foundation has proposed that $\mathrm{CM}$ be defined as migraine in the absence of drug abuse for which three or more types of migraine prophylaxis have been ineffective [3]. On a global scale, $\mathrm{CM}$ is related not only to an increased economic burden, i.e., a drain on medical resources, but also to lost productivity [4]. Peripheral subcutaneous injection of botulinum toxin has been shown to be effective as prophylaxis against CM [5] [6], and randomized, controlled studies of neuromodulation by percutaneous supraorbital stimulation in the absence of drug administration have shown the usefulness of this form of therapy [7]. We have focused on nondrug, percutaneous treatment and developed an oscillating mechanical stimulation therapy (OST), which broadly targets the craniocervical region and has been shown to be effective when administered at weekly intervals [8]. OST was originally attempted in Western countries as a form of physical therapy for medically refractory chronic pain, and a systematic review has been reported of its use in cases of calcific tendinitis of the rotator cuff [9]. There are very few studies from the field of migraine research, however.

\section{Material and Methods}

The safety of the technique used in the study was verified during preparatory research [8], and the study protocol was approved by the institutional review board of Shizuoka Red Cross Hospital (approval No. 2015-03), and this study was registered by the UMIN (ID: 00017253). The selected patients were given an oral and written explanation of the prospective trial, and they were enrolled between February 2016 and January 2017 after providing written informed consent.

\subsection{Patients}

The selected patients met the following inclusion criteria: 1) CM had been diagnosed according to the International Classification of Headache Disorders, $3^{\text {rd }}$ edition (beta version) [10]; 2) the CM was refractory, i.e., according to the patient's migraine diary or medical history, the headaches did not improve in severity or frequency, despite acute drug or prophylactic treatment; 3 ) the patient was $\geq 20$ years of age when providing consent; 4 ) the patient was deemed capable of outpatient visits; and 5) the patient's migraine drug dosage and method of 
administration remained unchanged during the 2-week period before the therapeutic intervention was begun. Refractory CM was defined as CM for which three types of grade A-recommended prophylactic drugs with different mechanisms of action were ineffective, in accordance with the Clinical Practice Guideline for Chronic Headache 2013 [11]. The patients underwent cervical spine radiography before and after OST, and safety was confirmed.

Patients not included in the study were 1) those with chronic headache other than CM; 2) those who were participating in another trial or had participated in another trial up to 1 month prior to the time the intervention would have been started; 3) those with concomitant compression of the spinal cord, resulting, for example, from a facial or craniocervical fracture; and those with severe cervical vertebral disease, intervertebral disc herniation, or ossification of the yellow ligament; 4) those with a history of osteoporosis; 5) those presenting with a severe cutaneous abnormality affecting the face, head, or neck; 6) those whose physical condition had deteriorated subsequent to massage or chiropractic adjustment to the craniocervical region; 7) those who had undergone surgical treatment for a cranial or spinal column disorder within the previous 6 months before this treatment; 8) those scheduled to undergo surgery during what would have been the treatment period; 9) those presenting with dementia; 10) those with malignancy requiring treatment; 11) those with psychological symptoms or a psychological disorder, such as severe confusion, hallucinations, delusions, or abnormal behavior; and 12) those who were pregnant.

\subsection{Method of Treatment}

OST was delivered by means of an electric percussion hammer (Hammons Impact; Aichi Electronics Industrial Co., Ltd., Aichi, Japan). Treatment was performed once a week over a period of 8 weeks. Each week, percutaneous mechanical OST was performed at several predetermined sites, so that by the end of the treatment period, OST had been performed twice at a total of 26 sites (Table 1 and Table 2): 13 on the face and head, 4 on the neck, and 9 on the upper back (Figure 1(a), Figure 1(b)). The device has been approved by the Ministry of Health, Labour and Welfare of Japan (approval no. 23B2X00010), and its use is not limited to specific disorders. It has been used to manage lumbar pain associated with intervertebral disc herniation, neck pain associated with acute sprain and cervical disc herniation, and rehabilitation after surgery for ligament rupture or fracture. In such cases, stimulation of $0.37 \mathrm{~N} 0.87 \mathrm{~N}$ is provided over a period of 2 to 3 months, and although the precise mechanism underlying the therapeutic effects is unknown, the stimulation is presumed to enhance the healing process.

Depending on the stimulation site, the patient is placed in the dorsal or prone position during treatment. The stimulus frequency is set to $6 \mathrm{~Hz}$, and the duration of OS at each site is 6 seconds. An OS intensity of 5 to 15 pounds is selected, depending on the site and the number of treatments. To ensure appropriate transmission of the oscillating mechanical stimulation based on the pressure and 
density of the tissue at the stimulation site, the stimulation depth is set to low, medium, or high. A single-prong, double-prong, or wide-prong head, which comes into contact with the patient's skin, is selected on the basis of the site of application.

For the study patients, if the migraine prophylaxis remained unchanged for 3 months before the start of OST and could be provided concomitantly, it was

Table 1. Oscillating craniocervical stimulation sites.

Sites on the face, head, and neck

1. Middle eyebrow: above the pupil

2. Infraorbital foramen: intersection of an imaginary vertical line through the pupil center and imaginary horizontal line through the lower end of the nasal wings

3. Nearby medial ocular angle: $3 \mathrm{~mm}$ above the medial ocular angle

4. Upper ear: apex of the head on the pinna

5. Upper lateral forehead: 4 digits from the lower edge of the sphenoidal rostrum

6. Lateral nostril: $1.5 \mathrm{~mm}$ from the lateral nostril

7. Medial eyelashes: excavation in medial edge on eyebrow

8. Lateral frontal area: $1 \mathrm{~cm}$ behind and $3 \mathrm{~cm}$ lateral to the midpoint of the frontal hairline

9. Supraorbital foramen: 1 digit above and $3 \mathrm{~cm}$ lateral to the upper center edge of the orbitas

10. Outer edge of the eyelashes: excavation in outer edge of the eyelashes

11. Lower edge of the zygomatic bone: lower zygomatic bone, directly below the outer canthus

12. Mental foramen: lower portion of the second premolars

13. Upper part of the gonial angle: 1 digit below the gonial angle

Sites on the back of the head and upper back

14. Lower portion of the mastoid process: posterior lower excavation of the mastoid process

15. External occipital protuberance: lateral excavation of the external occipital protuberance

16. Neighborhood of the spinous process of the second cervical vertebra: lower edge of the spinous process of the second cervical vertebra

17. Neighborhood of the spinous process of the first thoracic vertebra: lower edge of the spinous process of the first thoracic vertebra, 1.5 digits from the posterior median line

18. Neighborhood of the spinous process of the second thoracic vertebra: lower edge of the spinous process of the second thoracic vertebra, 1.5 digits from posterior median line

19. Neighborhood of the spinous process of the third thoracic vertebra: lower edge of the spinous process of the third thoracic vertebra, 1.5 digits from the posterior median line

20. Neighborhood of the spinous process of the fifth thoracic vertebra: lower edge spinous process of the third thoracic vertebra, 1.5 digits from the posterior median line

21. Scapula: one-third excavation from spina scapulae side on the imaginary line between the midpoint of both the spina scapulae and angulus inferior scapulae

22. Neighborhood of the spinous process of the fifth cervical vertebra: lateral lower cervical portion spinous of the seventh cervical vertebra, 2 digits from the posterior median sulcus

23. Lateral side of the spinous process of the second thoracic vertebra: lateral lower cervical portion spinous of the seventh cervical vertebra, 3 digits from the posterior median sulcus

24. Lateral side of the spinous process of the third thoracic vertebra: 3 digits from the lower edge of the posterior median line

25. Lateral side of the spinous process of the fourth thoracic vertebra: 3 digits from the lower edge of the posterior median sulcus

26. Lateral side of the spinous process of the fifth thoracic vertebra: 3 digits from the lower edge of the posterior median sulcus 
Table 2. Treatment schedule.

\begin{tabular}{ccc}
\hline Weeks & Patient position & Stimulation sites \\
\hline 1,2 & Dorsal & $1,2,3,6,12(\mathrm{~S})$ \\
& Prone & $4,5(\mathrm{~S}), 15(\mathrm{~W}), 16,17(\mathrm{D})$ \\
3,4 & Dorsal & $7,8,9,10,11,13,4,5(\mathrm{~S})$ \\
& Prone & $16(\mathrm{D}), 15(\mathrm{~W}), 18(\mathrm{D}), 19(\mathrm{D})$ \\
5,6 & Dorsal & $4,5,7,8,9,10,11,13(\mathrm{~S})$ \\
& Prone & $14(\mathrm{~S}), 22(\mathrm{D}), 23,24,25,26(\mathrm{~S})$ \\
7,8 & Dorsal & $4,5,7,8,9,10,11,13(\mathrm{~S})$ \\
& Prone & $16,17(\mathrm{D}), 21,23,24,25,26(\mathrm{~S})$ \\
\hline
\end{tabular}

(S), single probe; (D), double probe; (W), wide probe.

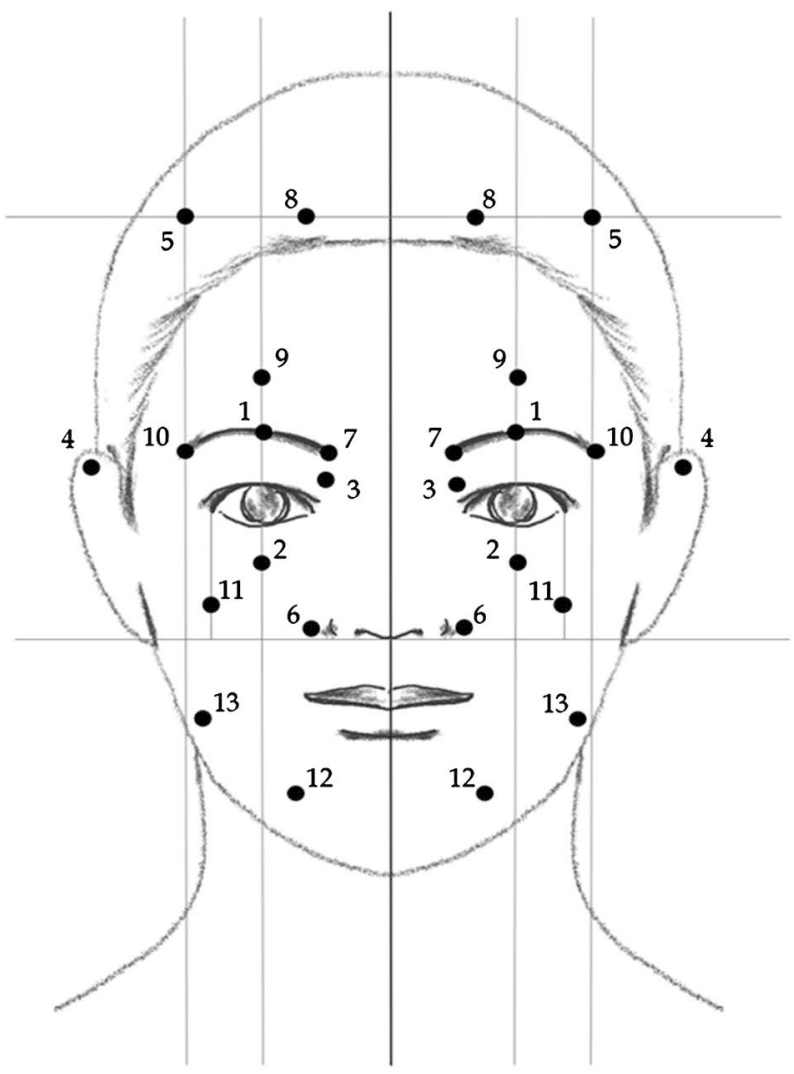

(a)

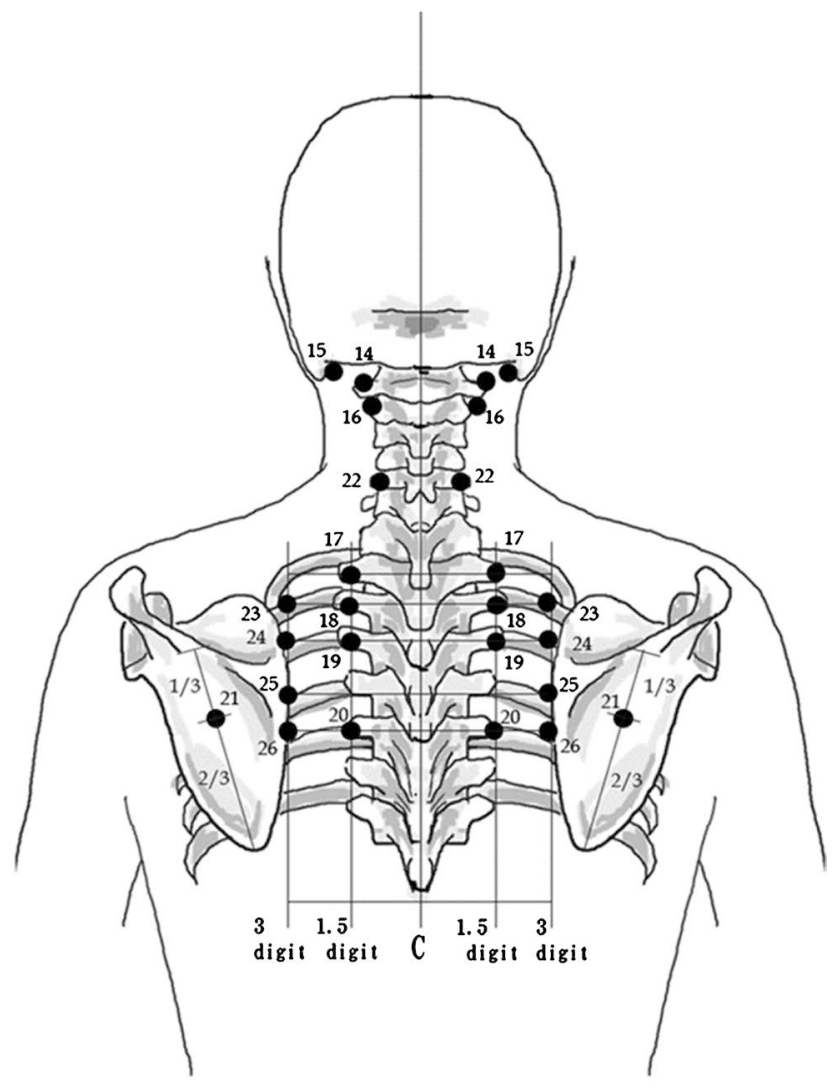

(b)

Figure 1. (a) Oscillating craniocervical stimulation sites in the front. 1, Middle eyebrow; 2, infraorbital foramen; 3, nearby medial ocular angle; 4, upper ear; 5, upper lateral forehead; 6, lateral nostril; 7, medial eyelashes; 8, lateral frontal area; 9, supraorbital foramen; 10, outer edge of the eyelashes; 11, lower edge of the zygomatic bone; 12, mental foramen; 13, upper part of the gonial angle. (b) Oscillating craniocervical stimulation sites in the back 14, Lower portion of the mastoid process; 15, external occipital protuberance; 16, neighborhood of the spinous process of the second cervical vertebra; 17 , neighborhood of the spinous process of the first thoracic vertebra; 18, neighborhood of the spinous process of the second thoracic vertebra; 19, neighborhood of the spinous process of the third thoracic vertebra; 20 , neighborhood of the spinous process of the fifth thoracic vertebra; 21 , scapula; 22 , neighborhood of the spinous process of the fifth cervical vertebra; 23, lateral side of the spinous process of the second thoracic vertebra; 24, lateral side of the spinous process of the third thoracic vertebra; 25 , lateral side of the spinous process of the fourth thoracic vertebra; 26 , lateral side of the spinous process of the fifth thoracic vertebra. 
continued during the treatment period. Drugs were used for migraine attacks but were not introduced for prophylaxis.

\subsection{Data Collection and Statistical Analysis}

For evaluation of OST, the following information was obtained: the patient's individual clinical characteristics (age, sex, migraine drug treatment); the number of migraine days, derived from the patient's headache diary; the Headache Impact Test (HIT-6) [12] and Visual Analog Scale (VAS) [13] scores; the frequency of acute therapy; and the allodynia score, derived from the Patient Health Questionnaire (PHQ-9) [14], Generalized Anxiety Disorder (GAD-7) [15], and allodynia scales. These study variables were obtained by neurologists before and after the start of treatment. Values are shown as means \pm SD. The HIT-6, VAS, and PHQ-9 scores were evaluated 3 and 6 weeks after the start of treatment. Changes in the HIT-6, VAS, GAD-7, PHQ-9, and allodynia scores were examined by one-way analysis of variance (ANOVA). SPSS version 21 (IBM SPSS Statistics for Windows; IBM Corp, Armonk, NY, USA) was used for statistical analysis, and $p<0.05$ was considered to indicate a significant difference.

\section{Results}

The clinical characteristics of the 10 enrollees are shown in Table 3. One patient

Table 3. Demographic and baseline characteristics.

\begin{tabular}{|c|c|c|c|c|c|c|c|c|c|c|}
\hline $\begin{array}{l}\text { Patient } \\
\text { No. }\end{array}$ & Gender & Age & $\begin{array}{l}\text { Number of Days } \\
\text { Headache Occurred } \\
\text { per Month }\end{array}$ & $\begin{array}{l}\text { HIT-6 } \\
\text { score }\end{array}$ & $\begin{array}{c}\text { Pain } \\
\text { Intensity } \\
\text { (VAS) Score }\end{array}$ & $\begin{array}{c}\text { GAD- } \\
7\end{array}$ & PHQ-9 & $\begin{array}{c}\text { Allodynia } \\
\text { scale }\end{array}$ & $\begin{array}{l}\text { Prophylactic } \\
\text { Medicaitons }\end{array}$ & Acute Medications \\
\hline 1 & M & 68 & 23 & 76 & 10 & 0 & 5 & 0 & Non & Zolmitriptan $2.5 \mathrm{mg}$ \\
\hline 2 & $\mathrm{~F}$ & 52 & 19 & 64 & 5 & 3 & 3 & 4 & $\begin{array}{l}\text { Lomerizine } 20 \mathrm{mg} \text {, } \\
\text { Propranolol } 40 \mathrm{mg}\end{array}$ & Naratriptan $2.5 \mathrm{mg}$ \\
\hline 3 & $\mathrm{~F}$ & 40 & 20 & 63 & 4 & 10 & 11 & 7 & Lomerizine $20 \mathrm{mg}$, & Naratriptan $2.5 \mathrm{mg}$ \\
\hline 4 & $\mathrm{~F}$ & 70 & 15 & 60 & 7 & 2 & 6 & 0 & Non & Sumatriptan $50 \mathrm{mg}$ \\
\hline 5 & $\mathrm{~F}$ & 48 & 28 & 78 & 9 & 22 & 18 & 1 & Non & $\begin{array}{c}\text { Sumatriptan } 50 \mathrm{mg}, \\
\text { Acetaminophen } 800 \mathrm{mg}\end{array}$ \\
\hline 6 & $\mathrm{~F}$ & 51 & 18 & 55 & 8 & 0 & 2 & 3 & $\begin{array}{l}\text { Amitriptyline } 25 \mathrm{mg} \text {, } \\
\text { Topiramate } 200 \mathrm{mg} \text {, } \\
\text { Valproic acid } 200 \mathrm{mg}\end{array}$ & $\begin{array}{l}\text { Aspirin } 900 \mathrm{mg}, \\
\text { Acetoaminophen } 600 \mathrm{mg} \text {, } \\
\text { Anhydrous caffeine } 200 \mathrm{mg} \text {, } \\
\text { Bromovalerylurea } 500 \mathrm{mg}\end{array}$ \\
\hline 7 & $\mathrm{~F}$ & 36 & 30 & 71 & 8 & 0 & 11 & 4 & Topiramate $100 \mathrm{mg}$ & Sumatriptan $50 \mathrm{mg}$ \\
\hline 8 & $\mathrm{~F}$ & 28 & 21 & 74 & 9 & 1 & 9 & 0 & $\begin{array}{l}\text { Amitriptyline } 50 \mathrm{mg} \text {, } \\
\text { Topiramate } 100 \mathrm{mg} \text {, }\end{array}$ & Loxoprofen $60 \mathrm{mg}$ \\
\hline 9 & $\mathrm{~F}$ & 30 & 27 & 66 & 8 & 6 & 17 & 6 & Amitriptyline $10 \mathrm{mg}$ & $\begin{array}{l}\text { Rizatriptan } 10 \mathrm{mg} \text {, } \\
\text { Acetaminophen } 800 \mathrm{mg} \text {, } \\
\text { Loxoprofen } 60 \mathrm{mg}\end{array}$ \\
\hline 10 & M & 25 & 15 & 66 & 10 & 15 & 12 & 5 & Lomerizine $20 \mathrm{mg}$ & Loxopfofen $60 \mathrm{mg}$ \\
\hline
\end{tabular}

One patient (patient No.10) withdrew from the study at the request of the family practitioner who wanted the patient to discontinue the treatment. Therefore, 9 patients completed the treatment. 
withdrew from the study at the request of the family practitioner who wanted the patient to discontinue the treatment. Nine patients completed the treatment. 9 patients completed the study protocol for 8 weeks. No severe or serious adverse events occurred.

Migraine frequency did not change after treatment; the mean frequency was $21.7 \pm 6.4$ days per month before treatment and $19.3 \pm 7.3$ days per month after treatment (Figure 2). However, the HIT-6 scores improved significantly from $67.0 \pm 8.2$ before treatment to $61.4 \pm 7.1(p=0.007)$ after 3 weeks, $61.1 \pm 11.5(p$ $=0.01)$ after 6 weeks, and $59.9 \pm 11.6(p=0.035)$ when treatment was completed (Figure 3(a)). Similarly, the VAS scores improved from $7.3 \pm 1.7$ before treatment to $5.9 \pm 2.9(p=0.044)$ after 3 weeks, $5.7 \pm 3.1(p=0.018)$ after 6 weeks, and $4.8 \pm 2.8(p=0.011)$ when treatment was completed. Notably, the VAS scores upon completion of treatment were significantly lower than those after 3 weeks $(p=0.011)$ (Figure 3(b)).

The GAD-7 (Figure 3(c)), PHQ-9 (Figure 3(d)), and allodynia scale scores obtained after 3 and 6 weeks of treatment were not significantly different from the scores obtained before and upon completion of treatment. There were also no significant changes in the patients' recorded use of acute therapy agents during the treatment period or in prophylactic treatment.

\section{Discussion}

This is the first study to verify the efficacy and safety of percutaneous craniocervical OST applied to multiple sites on the face, head, and neck to treat drug-resistant CM. The overall result of the study was that the patients' migraine symptoms decreased during the 8-week treatment period. Furthermore, OST therapy seems to

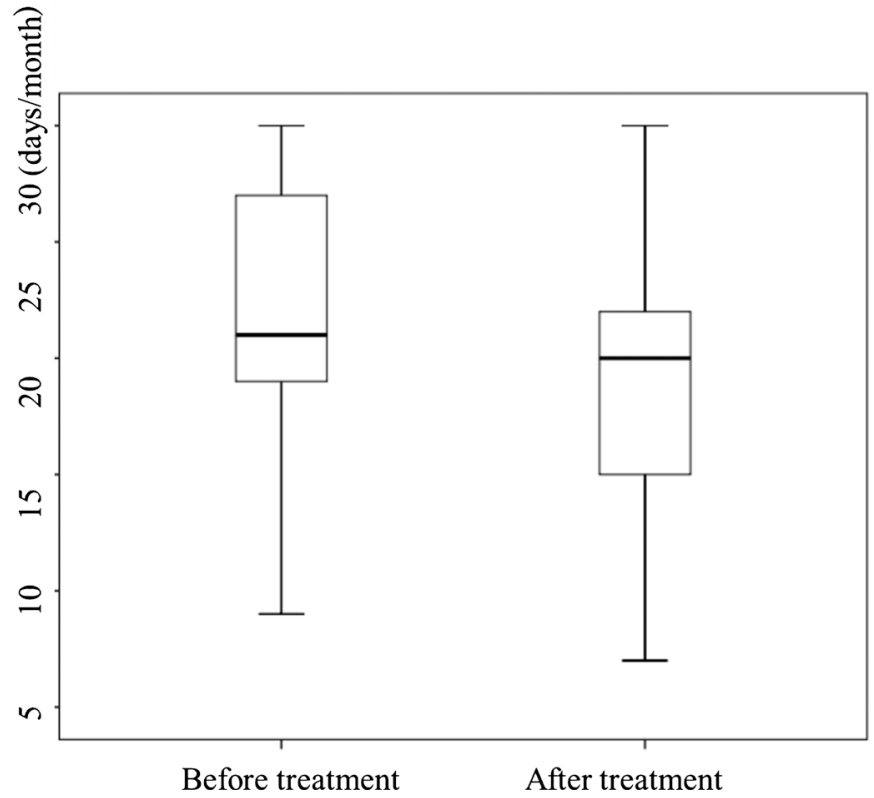

Figure 2. Migraine frequency. Box plots showing distribution of migraine frequency before and after treatment. Whiskers indicate the upper and lower quartiles. 
(a)

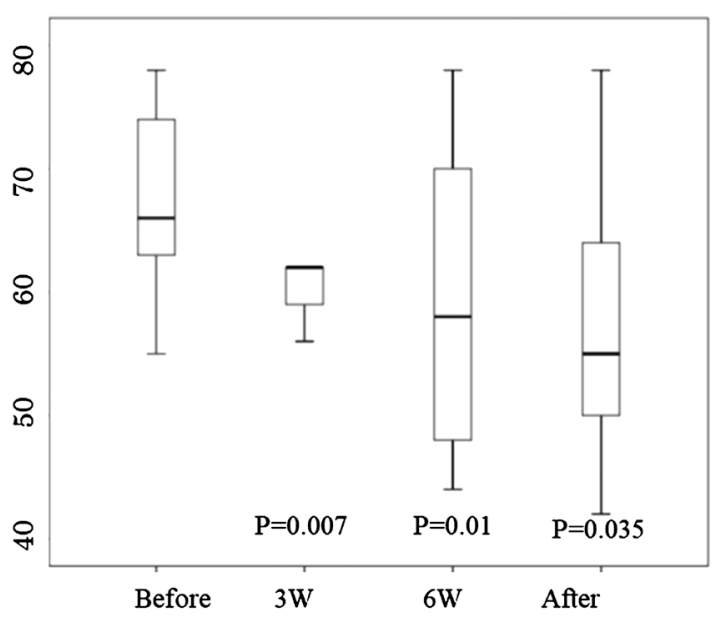

(c)

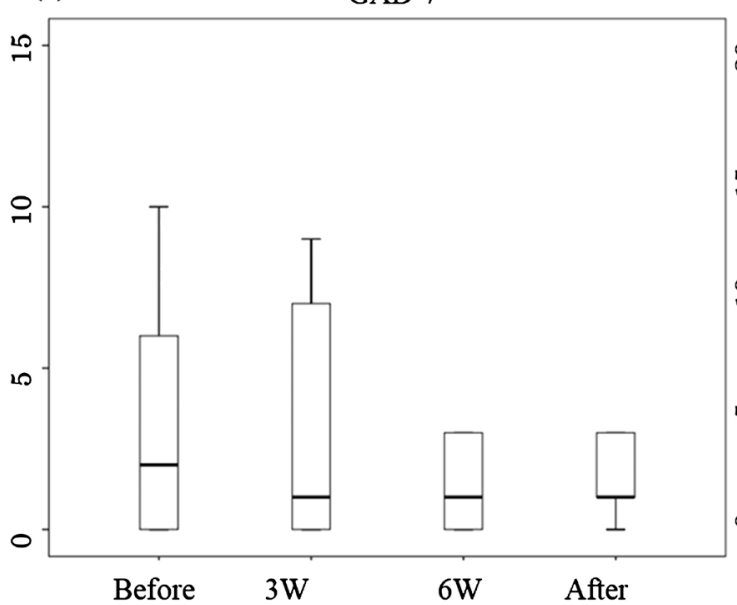

(b)

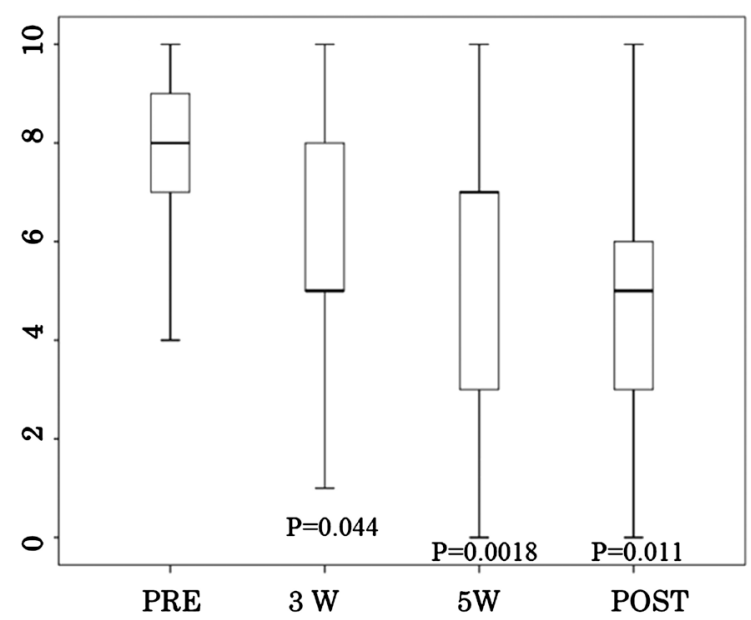

(d)

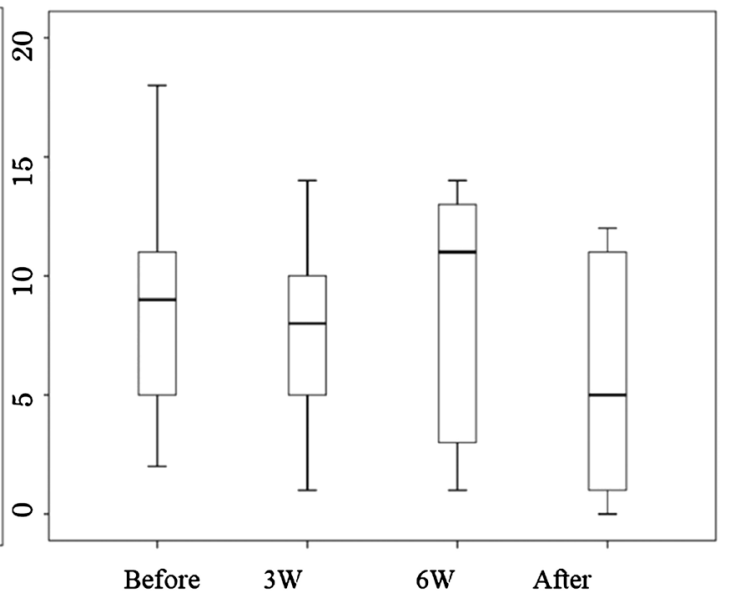

Figure 3. Clinical course of measurements. Box plots showing distribution of (a) HIT-6, (b) VAS, (c) GAD-7, and (d) PHQ-9 scores before treatment, after 3 and 6 weeks (W) of treatment, and after completion of treatment. Whiskers indicate the upper and lower quartiles.

be effective and well tolerated, it can be combined with drug treatments without risking cumulative adverse effects.

The outcome variables that changed after the start of craniocervical OST were the VAS score, which is an indicator of migraine severity, and the HIT-6 score, which is a quality of life (QOL) indicator related to migraines; both scores improved significantly. However, there was no obvious improvement in the number of migraine days and no significant improvement in the GAD-7 or PHQ-9 scores. We believe that the fact that the VAS and HIT-6 scores improved while the number of migraine days remained unchanged suggests that OST controls pain during attacks, despite having no effect on the cause of migraine, and that pain control improves QOL. Therefore, Patients with high VAS or HIT-6 score should be better treated by OST. We also believe that the absence of improvement in GAD-7 and PHQ-9 scores indicates that OST has no effect on psychological symptoms and that the treatment-based improvement in QOL is not due to psychogenic effects. The effects of noninvasive neurostimulation on migraine 
were shown in a study in which supraorbital stimulation therapy was used to treat infrequent migraines [7]; the number of migraine days decreased from 6.9 to 4.9. In another reported study, self-administration of noninvasive vagus nerve stimulation by 20 patients with drug-resistant migraine resulted in a decrease in the number of migraine days from 18 to 12 and improvement in depressive symptoms and sleep quality [16]. The OS used in our present study resulted in improved QOL that was attributed to a decrease in migraine severity. We expect, in the future, to see further improvement in the treatment of severe CM if we change the frequency and intensity settings for OS administration.

The mechanism underlying the effects of OST on CM remains unclear. OST is presumed to exert its effects when the stimulus is applied to the peripheral skin, and the main mechanism is assumed to be an effect on nociceptors located within the fascial tissue and intra- and extracranial muscles. Proposed mechanisms for the progression from sporadic migraines to CM include dysfunction of the periaqueductal gray matter that makes up the central descending nociceptive neural network [17] [18] and dysfunction of pain receptors, both due to central sensitization [19] [20]. Animal experiments have shown that the activity of vagal afferents is attenuated by nociceptive neural activity via the spinothalamic and spinoreticular tracts [21]. We presume that the OS applied in our study exerted its pain-modifying effects by passing from the body surface via the vagus nerve, occipital nerve, and trigeminal nerve, following pathways similar to those reported in a study that made concomitant use of percutaneous occipital nerve stimulation and percutaneous orbital stimulation, both of which rely on trigeminal stimulation [22]. Furthermore, we presume that OST also exerts effects on central sites related to chronic conversion of migraines, including the red nucleus, tectum, extrapyramidal system, and pathways descending from the pain matrix [23] [24], which have been verified both by their effects on the stimulation site and by functional magnetic resonance imaging (fMRI) and positron emission tomography (PET) studies.

Our findings should be interpreted in light of our study limitations. Only a small number of patients were included, and the study was not conducted as a randomized controlled trial. In addition, uniformity of the procedures between centers was not formally verified. Further, OS was applied at numerous sites on the face, head, and neck. The sites at which OS is particularly effective remain to be identified so that the number can be reduced for optimum clinical application and so that the therapeutic mechanism can be elucidated.

\section{Conclusion}

In conclusion, our data suggest that OS is well tolerated and may become a feasible form of treatment for drug-resistant CM. Further investigations are needed, however, for OST as treatment for refractory CM to become a clinical reality.

\section{Acknowledgements}

We also thank Tina Tajima, professor of the Research Institute of Medical Edu- 
cation, St. Marianna University School of Medicine for meticulous English editing.

\section{Conflicts of Interest}

The authors declare no conflicts of interest regarding the publication of this paper.

\section{References}

[1] Headache Classification Committee of the International Headache Society (HIS) (2013) The International Classification of Headache Disorders. 3rd Edition (Beta Version). Cephalalgia, 33, 629-808.

[2] Wang, S.J., Fuh, J.L., Lu, S.R., et al. (2000) Chronic Daily Headache in Chinese Elderly: Prevalence, Risk Factors, and Biannual Follow-Up. Neurology, 54, 314-319. https://doi.org/10.1212/WNL.54.2.314

[3] Martelletti, P., Katsarava, Z., Lampl, C., et al. (2014) Refractory Chronic Migraine: A Consensus Statement on Clinical Definition from the European Headache Federation. The Journal of Headache and Pain, 15, 47. https://doi.org/10.1186/1129-2377-15-47

[4] Lanteri-Minet, M. (2014) Economic Burden and Costs of Chronic Migraine. Current Pain and Headache Reports, 18, 385. https://doi.org/10.1007/s11916-013-0385-0

[5] Aurora, S.K., Dodick, D.W., Turkel, C.C., et al., PREEMPT 1 Chronic Migraine Study Group (2010) Onbotulinumtoxin A for Treatment of Chronic Migraine: Results from the Double-Blind, Randomized, Placebo-Controlled Phase of the PREEMPT 1 Trial. Cephalalgia, 30, 793-803. https://doi.org/10.1177/0333102410364676

[6] Diener, H.C., Dodick, D.W., Aurora, S.K., et al. (2014) Onbotulinumtoxin A for Treatment of Chronic Migraine; Results from the Double-Blind, Randomized, Placebo-Controlled Phase of the PREEMPT 2 Trial. Cephalalgia, 30, 804-814. https://doi.org/10.1177/0333102410364677

[7] Schoenen, J., Vandersmissen, B., Jeangette, S., et al. (2013) Migraine Prevention with a Supraorbital Transcutaneous Stimulator: A Randomized Controlled Trial. Neurology, 80, 697-704. https://doi.org/10.1212/WNL.0b013e3182825055

[8] Hotta, M., Shiraishi, M., Suzuki, T., Nishiyma, T. and Imai, N. (2016) Preliminary Study on the Effectiveness of Physical Therapy by Craniocervical Oscillating Stimulation for Chronic Headaches. Japanese Journal of Headache, 42, 177-181.

[9] Bannuru, R.R., Falvin, N.E., Vaysbrot, E., Harvey, W. and McAlindon, T. (2014) High-Energy Extracorporeal Shock-Wave Therapy for Treating Chronic Calcific Tendinitis of the Shoulder: A Systematic Review. Annals of Internal Medicine, 160, 542-549. https://doi.org/10.7326/M13-1982

[10] International Headache Society (2014) International Classification of Headache Disorders, 3rd Edition (Beta Version). Igaku-Shoin Ltd., Tokyo, 10-11.

[11] Clinical Practice Guideline for Chronic Headache 2013 (2014) Lists of Members of Chronic Headache Clinical Practice Guideline Development Committee, Members of Evaluation and Coordination Committee, Collaborating Societies. Igaku-Shoin Ltd., Tokyo, 114-117.

[12] Kosinski, M., Bayliss, M.S., Bjorner, J.B., et al. (2003) A Six-Item Short-Form Survey for Measuring Headache Impact: The HIT-6. Quality of Life Research, 12, 963-974. https://doi.org/10.1023/A:1026119331193 
[13] Katz, J. and Melzack, R. (1999) Measurement of Pain. Surgical Clinics of North America, 79, 231-252. https://doi.org/10.1016/S0039-6109(05)70381-9

[14] Muramatsu, K., Miyaoka, H., Kamijima, K., et al. (2007) The Patient Health Questionnaire, Japanese Version: Validity According to the Mini-International Neuropsychiatric Interview-Plus. Psychological Reports, 101, 952-960.

[15] Spitzer, R.L., Kroenke, K., Williams, J.B. and Löwe, B. (2006) A Brief Measure for Assessing Generalized Anxiety Disorder: The GAD-7. Archives of Internal Medicine, 22, 1092-1097. https://doi.org/10.1001/archinte.166.10.1092

[16] Kinfe, T.M., Pintea, B., Muhammad, S., et al. (2015) Cervical Non-Invasive Vagus Nerve Stimulation (nVNS) for Preventive and Acute Treatment of Episodic and Chronic Migraine and Migraine-Associated Sleep Disturbance: Preliminary Findings from a Prospective Observational Cohort Study. The Journal of Headache and Pain, 16, 101. https://doi.org/10.1186/s10194-015-0582-9

[17] Smith, G.S., Savery, D., Marden, C., et al. (1994) Distribution of Messenger RNAs Encoding Enkephalin, Substance P, Somatostatin, Galanin, Vasoactive Intestinal Polypeptide, Neuropeptide Y, and Calcitonin Gene-Related Peptide in the Midbrain Periaqueductal Grey in the Rat. Journal of Comparative Neurology, 350, 23-40. https://doi.org/10.1002/cne.903500103

[18] Welch, K.M., Nagesh, V., Aurora, S.K. and Gelman, N. (2001) Periaqueductal Gray Matter Dysfunction in Migraine: Cause or the Burden of Illness? Headache, 41, 629-637. https://doi.org/10.1046/j.1526-4610.2001.041007629.x

[19] Burstein, R. and Jakubowski, M. (2004) Analgesic Triptan Action in an Animal Model of Intracranial Pain: A Race against the Development of Central Sensitization. Annals of Neurology, 55, 27-36. https://doi.org/10.1002/ana.10785

[20] Yarnitsky, D., Goor-Aryeh, I., Bajwa, Z.H., et al. (2003) 2003 Wolff Award: Possible Parasympathetic Contribution to Peripheral and Central Sensitization during Migraine. Headache, 43, 704-714. https://doi.org/10.1046/j.1526-4610.2003.03127.x

[21] Chandler, M.J., Hobbs, S.F., Bloser, D.C. and Foreman, R.D. (1991) Effects of Vagal Afferent Stimulation on Cervical Spinothalamic Tract Neurons in Monkeys. Pain, 44, 81-87. https://doi.org/10.1016/0304-3959(91)90152-N

[22] Reed, K.L., Black, S.B., Banta, C.J. and Will, K.R. (2010) Combined Occipital and Supraorbital Neurostimulation for the Treatment of Chronic Migraine Headaches: Initial Experience. Cephalgia, 30, 260-271. https://doi.org/10.1111/j.1468-2982.2009.01996.x

[23] Welch, K.M., Cao, Y., Aurora, S.K., Wiggins, G. and Vikingstad, E.M. (1998) MRI of the Occipital Cortex, Red Nucleus and Substantia Nigra during Visual Aura of Migraine. Neurology, 51, 1465-1469. https://doi.org/10.1212/WNL.51.5.1465

[24] Weiller, C., May, A., Limmroth, V., et al. (1995) Brain Stem Activation in Spontaneous Human Migraine Attacks. Nature Medicine, 1, 658-660.

https://doi.org/10.1038/nm0795-658 